\title{
Impact of COVID-19 pandemic on psychological health of a sample of the health care workers in the western region of Kingdom of Saudi Arabia
}

\author{
Sadia Sultan ${ }^{1^{*}} \mathbb{D}$, Abu Bashar ${ }^{2}$, Ibtesam Nomani ${ }^{3}$, Aisha Tabassum ${ }^{4}$, Mohammad Shahid lqbal $^{4}$, \\ Ebtihaj O. Fallata ${ }^{5}$, Ramya Ahmad Sindi ${ }^{4}$, Nouf M. Almasoudi ${ }^{4}$ and Seeqa Rheem ${ }^{6}$
}

\begin{abstract}
Background: The coronavirus disease 2019 pandemic has shown a significant impact on the psychological wellbeing of health care workers. The aim of the study was to evaluate the impact of the COVID-19 pandemic on the psychological health of health care workers in the Kingdom of Saudi Arabia. During the months of November and December, 283 health care workers completed a survey containing measures of depression, anxiety and stress (using Depression Anxiety and Stress-21 scale [DASS-21]) and questions regarding potential predictors such as the role of COVID-19 perception, availability of mental health support and work-related factors. Pearson $X^{2}$ test revealed factors associated with the presence of significant psychiatric symptoms.

Result: Among the participants, $17.3 \%$ screened positive for depression, $26.2 \%$ for anxiety and $17.3 \%$ for stress. Nurses reported significantly more depression, anxiety and stress than doctors. Those who received mental health support reported significantly lesser depression, anxiety and stress. Those who felt that quality of life was heavily impacted due to COVID-19 reported significantly high depression, anxiety and stress.
\end{abstract}

Conclusions: Poor psychological well-being was prevalent in health care workers; however, mental health measures have been shown to significantly reduce the mental health burden in health care workers.

Keywords: COVID-19, Psychological health, Health care workers, Pandemic, Depression, Anxiety, Stress

\section{Background}

The coronavirus disease 2019 (COVID-19) has emerged as a highly devastating infectious disease, which was declared as a pandemic by the World Health Organization in March 2020 [1]. Infectious disease outbreaks are known to cause a psychological impact on healthcare workers as well as the general population. A noteworthy example would be the

\footnotetext{
*Correspondence: drsaddy2003@yahoo.com

${ }^{1}$ Clinical Science Department, Fakeeh College for Medical Sciences, Jeddah, Saudi Arabia

Full list of author information is available at the end of the article
}

psychological impact observed during the severe acute respiratory syndrome (SARS) outbreak in 2007 [2-4]. This pandemic in itself can be considered as a traumatic event owing to its physical, emotional and psychological effects [5]. Moreover, the policies devised to counter its spread introduced new stressors and turmoil in the daily life of most people around the globe. The stay home advisory, social distancing and economic issues such as unemployment further affected the psychological well-being.

A survey study found that the prevalence of depressive symptoms in the USA increased more than 3 -fold [6] and mental stress rose by nearly 1 -fold [7] in the 
UK population during the COVID-19 pandemic. Since the start of the pandemic, health care workers (HWCs) have been overburdened with increased workload all over the world. Limited resources, long shifts, sleep deficit, and direct exposure to patients are among the factors leading to psychological illness such as PTSD, anxiety, stress and depression [8-13]. The psychological impact was noted more in elderly, female sex, those with medical comorbidity and non-medically trained professionals [14, 15]. Quite a few studies have reported psychological impact in health care workers $(\mathrm{HCW})$ in the region of Saudi Arabia. The rationale of the study is to understand the magnitude of the psychological impact of the COVID-19 outbreak among health care workers, which is crucial in guiding policies and interventions to maintain their psychological wellbeing. The aim of our study is to evaluate the psychological impact and its determinants on HCW.

\section{Methods}

\section{Study setting and population}

This was a cross-sectional online survey study, in which data was collected from 1 November to 30 December 2020. The online survey questionnaire was circulated using e-mail, WhatsApp and Twitter. The survey was sent as google forms to various HCWs at different hospitals across Saudi Arabia, and they were requested to forward it further. All participants willing to participate in the study completed the questionnaire. The survey was administered once and there was no subsequent follow-up. Institutional review board of Umm Al-Qura University exempted the study from ethical approval since it was a crosssectional survey study.

\section{Outcome measures}

\section{Survey questionnaire}

The questionnaire was developed by researchers along with a pilot group of $10 \mathrm{HCWs}$, and 23 questions were included based on expert opinion. Section one of the questionnaire included the participants' baseline information, department and designation at work and previous experience of work during epidemic or pandemic. Section 2 included exposure-related information and ease of getting tested for COVID-19. Section 3 included practices and perception about the illness, satisfaction with training received, provision of adequate PPE, updated guidelines in treatment and availability of mental health support. Section 4 included questions regarding work load and impact on quality of life. The questionnaire was administered in the English language.

\section{Depression Anxiety Stress Scale-21}

Psychological outcomes were assessed using Depression Anxiety Stress Scales (DASS-21). DASS-21 is a screening tool used for screening depression, anxiety and stress in the general population. It is a self-administered 21-item instrument created by the University of New South Wales, Australia, which screens for depression, anxiety and stress based on the recommended severity thresholds for depression, anxiety and stress subscales [16]. For the purpose of this study, we examined depression, anxiety and stress with cut-off scores of $>9,>6$ and $>10$, respectively. Each subscale was composed of seven items, and each response was rated from 0 to 3 , where 0 indicated 'Did not apply to me' and 3 indicated 'Applied to me most of the time.' Items $3,5,10,13,16,17$, and 21 formed depression subscales. In the depression subscales, scores of 0-9 were considered 'normal', 10-12 as 'mild', $13-20$ as 'moderate', $21-27$ as 'severe' and 28-42 as 'extremely severe'. Items 2, 4, 7, 9, 15, 19 and 20 formed anxiety subscales. The anxiety sub-scores were categorized as, 'normal' (0-6) 'mild' (7-9), 'moderate' (10-14), 'severe' (15-19) and 'extremely severe' (20-42). Items 1 , $6,8,11,12,14$ and 18 formed stress subscales. The stress subscale scores were categorized into 'normal' $(0-10)$, 'mild' (11-18), 'moderate' (19-25), 'severe' (26-33) and 'extremely severe' (>34) stress. This scale has been shown to have adequate validity and reliability $[17,18]$ and was used in various studies evaluating psychological impact in the Saudi population $[13,19]$. Participants were asked to report the presence of a symptom over the past week. Scores for three emotional states were calculated by adding the points for the relevant items (questions $3,5,10$, $13,16,17,21$ for depression; questions $1,6,8,11,12,14$, 18 for stress; questions $2,4,7,9,15,19,20$ for anxiety) and double up [18].

\section{Outcomes}

The primary study outcome was the prevalence of depression, anxiety and stress reported among HWCs during the COVID-19 pandemic. Subsequently, we explored the determinants of these psychological outcomes.

\section{Statistical analysis \\ Sample size calculation sampling and recruitment strategy} A total of 228,171 HCWs, including Saudis and non-Saudis, are in the $\mathrm{MOH}$. The estimated number of frontline participants in the COVID-19 team is 30\% of the total number of participants $(68,451)$. A recently published study by Alhurishi et al. [19] on psychological distress among the healthcare providers in Saudi Arabia reported a prevalence of $76 \%$. Taking this prevalence, at the $95 \%$ confidence interval with a margin of error of $5 \%$ and 
power as $80 \%$, the concluded sample size was 281 using OpenEpi software (www.OpenEpi.com). We used the following equation for calculating the sample size: thought the training was insufficient. Fifty per cent felt that HCWs have an unconditioned obligation to fulfil duties and $42 \%$ reported provision of institutional mental

$$
\text { Sample size } n=[\operatorname{DEFF} * \operatorname{Np}(1-p)] /\left[\left(d^{2} / Z^{2}{ }_{1-\alpha / 2} *(N-1)+p *(1-p)\right]\right.
$$

Snowball sampling technique was used to recruit the participants. Inclusion criteria were restricted to HCWs. Platforms including Facebook, WhatsApp and Twitter, as well as personal e-mail, were used for the recruitment and dissemination. Potential study participants were approached via IRB-approved messages containing a link to the survey shared on the aforementioned social media. Study participants were also asked to share the link with their colleagues via personal networks

The data collected through google forms was extracted in the Excel sheets and analysis was performed by SPSS software, version 21.0 IBM. Descriptive statistics was performed for socio-demographics and COVID-19-related characteristics. Means of DASS-21 subscales and the standard deviations were also calculated. The Pearson $X^{2}$ test and Student $t$ test were used to compare categorical and continuous outcomes, respectively, between the two groups. $P$ value less than 0.05 was taken as statistically significant.

\section{Results}

\section{Participant characteristics}

After the questionnaire was circulated through social media platforms such as e-mail, WhatsApp and Twitter, 305 responses were obtained, out of which 283 responses were complete and were included for analysis. Out of this sample, $71 \%$ were doctors, $14.5 \%$ nurses and $14.5 \%$ other hospital staff including technicians and physiotherapists. Out of these, $24.4 \%$ of the participants were working in the emergency department and intensive care units and $29.4 \%$ of them had previous experience of working during any epidemic. $77.8 \%$ of the sample was exposed to COVID-19 among which 47.6\% developed COVID19-related symptoms (Table 1). With regard to attitudes, practices and perception of COVID-19 (Table 2), $68.3 \%$ stopped working after exposure whereas $10 \%$ kept working voluntarily and $20 \%$ were asked to work by the hospital. $54.45 \%$ were tested for COVID-19 and $66.7 \%$ reported easy accessibility for testing. Regarding the perception about COVID-19, 24.45\% considered it a mild illness, $45.6 \%$ as moderate and $30 \%$ perceived it as a severe illness. $56.2 \%$ reported being trained specifically for COVID-19 management among which $38.45 \%$ health support. $41.3 \%$ reported they were pushed beyond their training and $82.7 \%$ felt that work was impacting their household activity. Surprisingly, only $28.3 \%$ felt that work during COVID-19 has a negative impact on quality of life (Table 2).

\section{Psychological impact}

During the COVID-19 pandemic, 49 (17.3\%) participants of our study cohort of healthcare workers screened positive for depression, 90 (26.2(\%) for anxiety and 49 (17.3\%) for stress disorders. Among the participants screening positive on the depression subscale, 44 (15.5\%) had mild and $5(1.8 \%)$ had moderate depression while none suffered from severe or extremely severe depression (Fig. 1). Similarly, among the participants screening positive on the anxiety subscale, $49(17.3 \%)$ reported mild, $29(10.2 \%)$ moderate, $12(4.2 \%)$ severe and 1 (0.3\%) extremely severe anxiety (Fig. 2). Among the participants screening positive on the stress subscale, $23(8.1 \%)$ reported mild, 25 $(8.8 \%)$ moderate and $1(0.3 \%)$ severe stress with no participant reporting very severe stress (Fig. 3).

Mean depression, anxiety and stress scores of the participants were $6.05 \pm 4.96,4.79 \pm 4.70$ and $5.10 \pm 4.84$, respectively (Table 2).

\section{Determinants of depression, anxiety and stress}

Depression $(p=0.002)$, anxiety $(p=0.000)$ and stress $(p=0.04)$ were significantly higher among nurses when compared to doctors. Surprisingly, working in the emergency and intensive care units was not significantly associated with high scores on depression, anxiety and stress. Having experience working during any previous epidemics was significantly associated with increased anxiety $(p=0.004)$. Those who received mental health support reported significantly lesser depression $(p=0.007)$, anxiety $(p=0.001)$ and stress $(p=0.002)$. Feeling of being pushed beyond training was significantly $(p=0.0004)$ associated with a high level of anxiety. Those who felt that quality of life was heavily impacted due to COVID19 reported significantly high depression $(p=0.003)$, anxiety $(p=0.07)$ and stress $(p=0.001)$. Other factors such as being tested positive for COVID-19, perception about the illness, having adequate training, knowing adequate guidelines for managing COVID-19, availability of adequate PPE, being engaged with COVID-related activities 
Table 1 Socio-demographic and COVID-19-related characteristics of the participants $(N=283)$

\begin{tabular}{|c|c|c|}
\hline SI. No. & Variables & $\begin{array}{l}\text { Frequency } \\
\text { (percentages) } \\
N(\%)\end{array}$ \\
\hline \multirow[t]{4}{*}{1.} & Type of Healthcare Professional & \\
\hline & Doctor & $201(71.0)$ \\
\hline & Nurse/Nurse Practitioner & $41(14.5)$ \\
\hline & Others & $41(14.5)$ \\
\hline \multirow[t]{2}{*}{2.} & Location & \\
\hline & Western region of Saudi Arabia & $283(100 \%)$ \\
\hline \multirow[t]{3}{*}{3.} & Primary working in the Emergency $D$ & \\
\hline & Yes & $69(24.4)$ \\
\hline & No & $214(75.6)$ \\
\hline \multirow[t]{3}{*}{4.} & Have experience of working during & 9, MERS 2012) \\
\hline & Yes & $87(29.4)$ \\
\hline & No & $196(70.6)$ \\
\hline \multirow[t]{3}{*}{5.} & Exposed to at least one person wh & ection \\
\hline & Yes & $196(77.8)$ \\
\hline & No & $56(22.2)$ \\
\hline \multirow[t]{3}{*}{6.} & Experienced flu-like symptoms or s & \\
\hline & Yes & $120(47.6)$ \\
\hline & No & $132(52.4)$ \\
\hline \multirow[t]{3}{*}{7.} & Tested for COVID-19 & \\
\hline & Yes & $229(78.4)$ \\
\hline & No & $54(21.6)$ \\
\hline \multirow[t]{4}{*}{8.} & Tested positive for COVID-19 & \\
\hline & Yes & $32(11.3)$ \\
\hline & No & $197(67.1)$ \\
\hline & Didn't undergo test & $54(21.6)$ \\
\hline \multirow[t]{6}{*}{9.} & Engaged in COVID-19-related w & \\
\hline & $1-30$ days & $67(23.7)$ \\
\hline & $31-60$ days & $31(10.9)$ \\
\hline & $61-90$ & $23(8.1)$ \\
\hline & $91+$ days & $84(29.7)$ \\
\hline & Not engaged in COVID-19 work & $78(27.6)$ \\
\hline
\end{tabular}

for more than a month and ability to perform household activities were not significantly associated with an increase in DASS-21 scores (Tables 3 and 4).

\section{Discussion}

The present study represents the psychological impact on HCWs in the western region of the Kingdom of Saudi Arabia. Furthermore, it investigated the determinants of the psychological impact among HCWs. We found depression in $17 \%$, anxiety in $32 \%$ and stress in $17 \%$. Our study reported lesser depression (17\%) compared to other studies that reported 55.2\% [20] and $50.8 \%$ [20] depression. In our study, we found anxiety in (32\%) which is again less when compared to 51.4\% [21], $50.4 \%$ [20] and $68.25 \%$ [22] anxiety reported in previous studies. Evidence suggests 27.3\% [23] and 62.3\% [24] stress among HCWs, which is higher compared to our study. The lesser levels of depression, anxiety and stress reported in our study could be due to the timing at which the study was performed. Since our study was performed at the time, the COVID-19 cases were showing a downward trend when compared to the studies done when the cases were at a peak. However, factors such as personality types, coping skills and differences in tools used to measure psychological impact could be another reason for such variation in findings.

Our study showed significantly increased levels of depression $(p=0.002)$, anxiety $(p=0.000)$ and stress $(p=0.004)$ in nurses than doctors which is in line with the previous studies that reported increased 
Table 2 Practices and perceptions of healthcare professionals during the COVID-19 pandemic $(N=283)$

\section{SI. No. Attitude/practice-related characteristics}

1. Did you stop working if you experienced symptoms suggestive of COVID-19 infection?(Out of 132)

Yes

No

2. What did you do after you developed symptoms suggestive of COVID-19? (multiple responses)

Voluntarily self-quarantined only

My institution told me to stay at home

My institution told me to keep working

$24(20.0)$

I voluntarily kept working

$12(10.0)$

3. How easy was it to get tested for COVID-19 in your respective settings?

Easy

Not easy nor difficult

Difficult

4. What is your current perception towards COVID-19 as a disease?

Milder infection

Moderate disease

$129(45.6)$

Severe disease

5. Have you had any specific training related to the COVID-19 pandemic?

Yes

$159(56.2)$

No

$124(43.8)$

6. If you received any training related to the COVID-19 pandemic, do you feel the training was sufficient?(out of 159)

Yes

No

7. Did you receive appropriate guidelines on updated procedures related to personal safety to follow at work?

Yes

No

8. Did your institution provide you adequate PPE (personal protective equipment)?

Yes

No

9. Extent to which you agree with the statement: Healthcare workers have unconditional obligations to work, even when the risks to themselves are great

Strongly agree

$50(17.7)$

Agree

$58(20.6)$

Somewhat agree

$44(15.7)$

Neither agree nor disagree

$35(12.4)$

Somewhat agree

Disagree

$37(13.1)$

Strongly disagree

10. Has your institution made psychological or mental health support available to you?

Yes

No

11. Did you experience a moment whereby you had to make a prioritizing decision about vital issues (ICU admission, intubation, etc.) due to shortage of medical supplies?

Yes

No

$150(53.0)$

Not applicable

$86(13.4)$

12. Are you feeling to get pushed beyond your training?

Yes 
Table 2 (continued)

\section{SI. No. Attitude/practice-related characteristics}

13. Work have negative impact on QoL because of COVID-19

Yes

No

14. Work impacting household activities because of COVID-19

Yes

No

$49(17.3)$

\section{Depression}

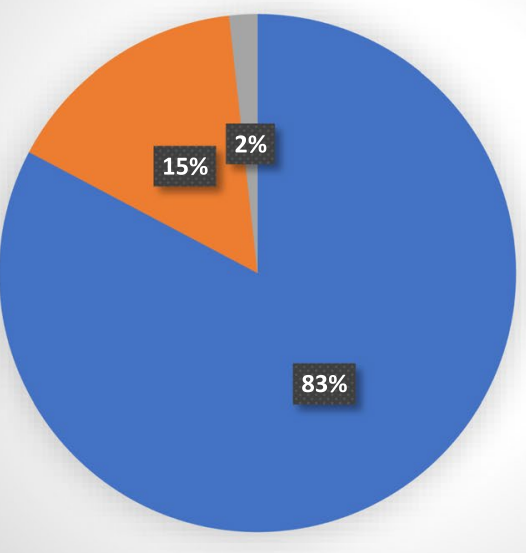

Normal

Mild

Moderate

Fig. 1 Prevalence and severity of depression among the healthcare professionals using DASS-21 ( $N=283)$

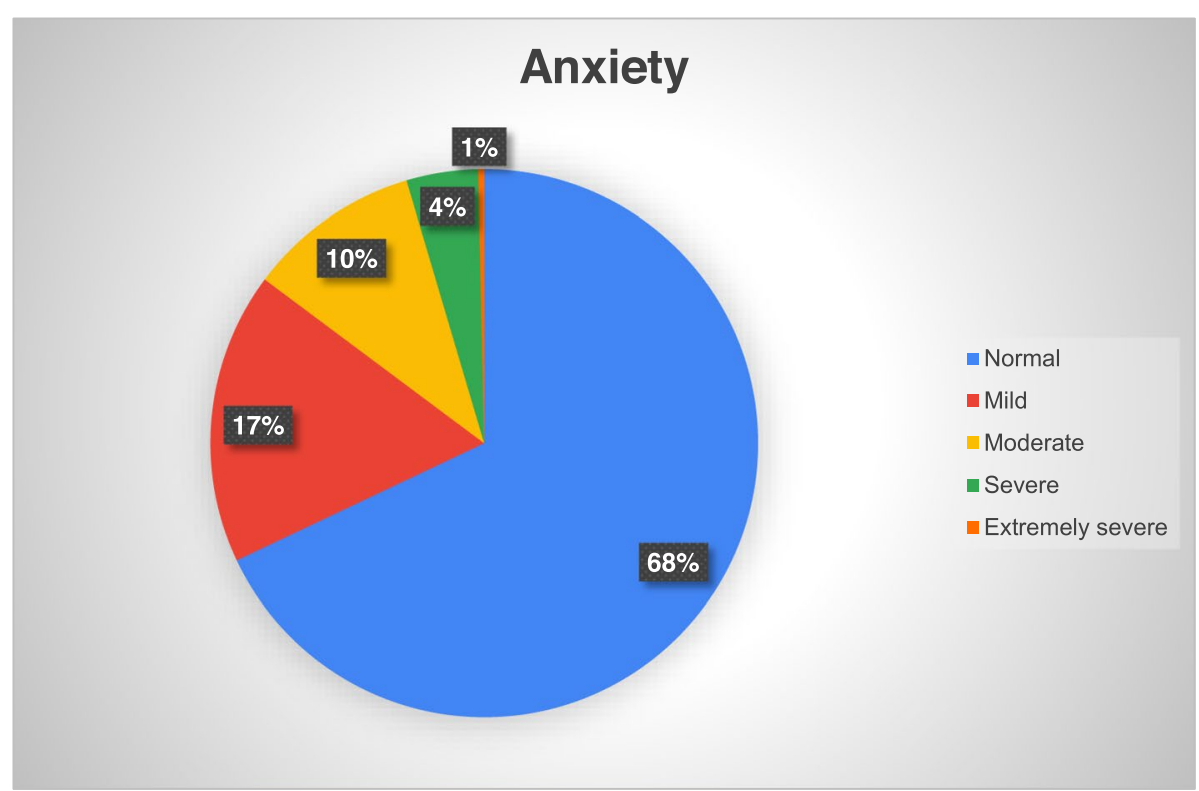

Fig. 2 Prevalence and severity of anxiety among the healthcare professionals using DASS-21 ( $N=283$ ) 


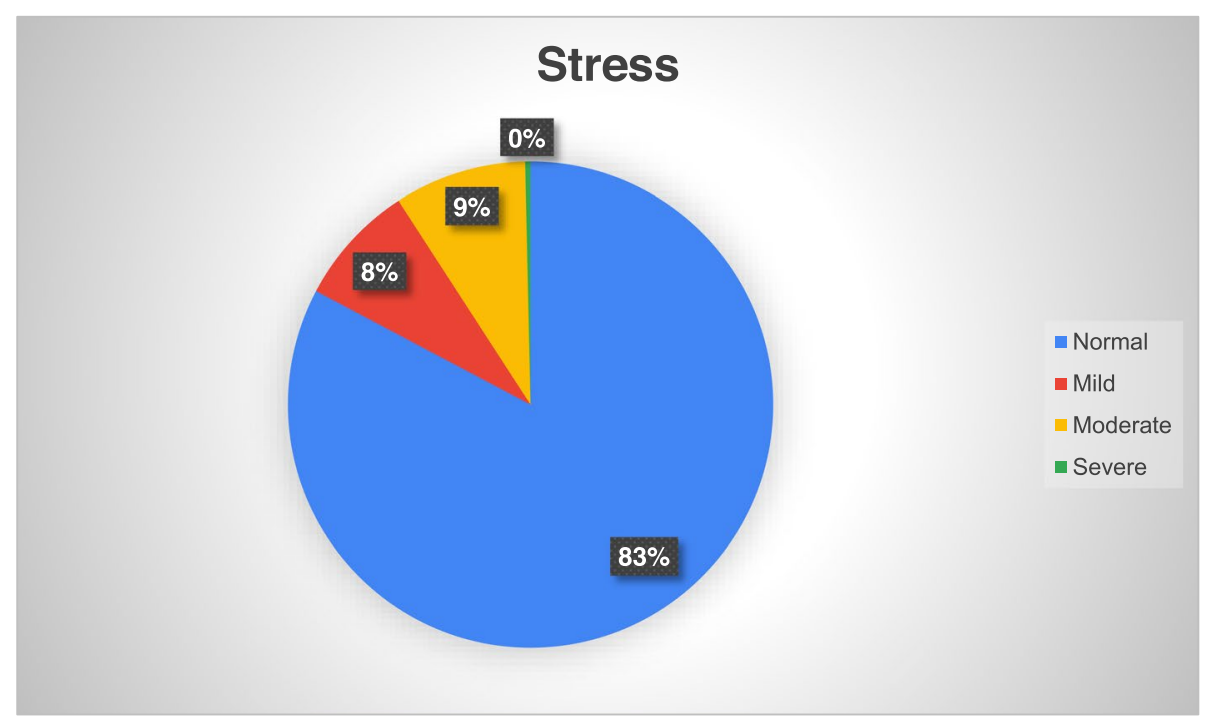

Fig. 3 Prevalence and severity of stress among the healthcare professionals using DASS-21 ( $N=283)$

Table 3 Mean scores of depression, anxiety and stress among the healthcare professionals using DASS-21 ( $N=283)$

\begin{tabular}{llll}
\hline & Depression & Anxiety & Stress \\
\hline Mean \pm SD & $6.05 \pm 4.96$ & $4.79 \pm 4.70$ & $5.10 \pm 4.84$ \\
Range & $0-21$ & $0-20$ & $0-21$ \\
\hline
\end{tabular}

psychological impact among nurses [20, 21]. Previous studies that were conducted during the SARS outbreak also reported higher levels of anxiety and depression in nurses than doctors $[25,26]$. Alternate findings were depicted in previous studies during SARS where doctors reported more stress and anxiety compared to nurses $[27,28]$. Lack of family support and social isolation had a negative psychological impact on nurses who chose to self-isolate while at work [27]. The factors contributing to more mental health burden among nurses could be due to female sex conferring a greater burden of depression, anxiety and stress [29-31], being in close contact to COVID-19 patients [32-34] and long work hours [35]. Studies suggest that being in close contact with the patient is 1.4 times more likely to cause fear and twice more likely to cause anxiety and depression when compared to non-clinical staff [36]. Other factors causing increased psychological impact in HCWs are increased distress due to the burden of adhering to strict protective measures [37], stigmatization from family members and neighbourhood because of their work in hospital [38]. Being exposed to contagion, colleagues getting quarantine, colleagues dying of
COVID-19 was found to be associated with increased depression, insomnia and PTSD [39]. The biggest cause for worry was family and friends becoming ill or dying from COVID-19. This suggests the need for additional support for personnel in these roles. Interestingly, working in emergency care and intensive care unit was not associated with high depression, anxiety and stress in our study which is in contrast to other studies reporting more psychological impact in those working in emergency and ICU [21]. This could be again due to the reduced load of cases during the period of our study.

The most striking finding of our study depicting significantly lesser depression $(p=0.007)$, anxiety $(p=0.001)$ and stress $(p=0.002)$ among those who received mental health support explains the importance of psychological interventions needed for the mental well-being of HCWs. Psychological support and practical support with insurance and compensation matters had a protective effect against stress [3]. Resilience and coping for health care community ( $\mathrm{RCHC}$ ) intervention has demonstrated efficacy at reducing negative mental health impact among healthcare workers, producing positive psychological outcomes of increased perceived knowledge and social support and decreased acute stress levels [40]. In light of recent systematic reviews, eye movement desensitization and reprocessing and trauma-focused cognitive behavioural therapy are among the most effective programmes targeting psychological symptoms [41, 42]. However, it was beyond the scope of our study to find what strategies were used in the institutional mental health support extended to the HCWs. Although, it is evident that 
Table 4 Determinants of depression, anxiety and stress among the healthcare professionals $(N=283)$

\begin{tabular}{|c|c|c|c|c|c|c|c|c|c|}
\hline \multirow[t]{2}{*}{ Variables } & \multicolumn{3}{|c|}{ Depression } & \multicolumn{3}{|l|}{ Anxiety } & \multicolumn{3}{|l|}{ Stress } \\
\hline & $\begin{array}{l}\text { Present } \\
(n=49) \\
N(\%)\end{array}$ & $\begin{array}{l}\text { Absent } \\
(n=234) \\
N(\%)\end{array}$ & $p$ value & $\begin{array}{l}\text { Present } \\
(n=90) \\
N(\%)\end{array}$ & $\begin{array}{l}\text { Absent } \\
(n=193) \\
N(\%)\end{array}$ & $p$ value & $\begin{array}{l}\text { Present } \\
(n=49) \\
N(\%)\end{array}$ & $\begin{array}{l}\text { Absent } \\
(n=234) \\
N(\%)\end{array}$ & $p$ value \\
\hline \multicolumn{10}{|l|}{ Type of healthcare professional } \\
\hline Doctor & $26(7.7)$ & $17592.3)$ & 0.002 & $47(23.4)$ & $154(76.6)$ & $<0.000$ & $29(14.4)$ & $172(85.6)$ & 0.04 \\
\hline Nurses & $2328.0)$ & $59(72.0)$ & & $43(52.4)$ & $39(47.6)$ & & $20(24.4)$ & $62(75.6)$ & \\
\hline \multicolumn{10}{|c|}{ Primary work in the Emergency (ER/UC) or Intensive Care Unit } \\
\hline Yes & $16(23.2)$ & $53(76.8)$ & 0.14 & $25(36.2)$ & $44(63.8)$ & 0.36 & $17(24.6)$ & $52(75.4)$ & 0.06 \\
\hline No & $33(15.4)$ & $181(84.6$ & & $65(30.4)$ & $149(69.6)$ & & $32(14.9)$ & $182(85.1)$ & \\
\hline \multicolumn{10}{|c|}{ Having experience of working during any of the previous epidemics or pandemics } \\
\hline Yes & $19(21.8)$ & $68(78.2)$ & 0.18 & $38(43.7)$ & $49(56.3)$ & 0.004 & $15(17.2)$ & $72(82.8)$ & 0.98 \\
\hline No & $30(15.3)$ & $166(84.7)$ & & $52(26.5)$ & $144(72.4)$ & & $34(17.3)$ & $162(82.7)$ & \\
\hline \multicolumn{10}{|l|}{ Tested positive for COVID-19 } \\
\hline Yes & $6(18.8)$ & $26(81.2)$ & 0.82 & $14(43.7)$ & $18(56.3)$ & 0.12 & $8(33.3)$ & $24(66.7)$ & 0.22 \\
\hline No & $43(17.1)$ & $208(82.9)$ & & $76(30.3)$ & $175(69.7)$ & & $41(16.3)$ & $210(83.7)$ & \\
\hline \multicolumn{10}{|c|}{ Perception of COVID-19 as a disease } \\
\hline Mild/benign infection & $14(20.3)$ & $55(79.7)$ & 0.45 & $22(31.9)$ & $47(68.1)$ & 0.98 & $11(15.9)$ & $58(84.1)$ & 0.43 \\
\hline Moderate/severe disease & $35(16.3)$ & $179(83.7)$ & & $68(31.8)$ & $146(68.2$ & & $38(17.7)$ & $176(82.3)$ & \\
\hline \multicolumn{10}{|c|}{ Received specific training for COVID-19 } \\
\hline Yes & $31(19.5)$ & $128(81.5)$ & 0.27 & $49(30.8)$ & $110(69.2)$ & 0.68 & $28(17.6)$ & $131(82.4)$ & 0.71 \\
\hline No & $18(14.5)$ & $106(85.5)$ & & $41(33.1)$ & $83(66.9)$ & & $21(16.9)$ & $103(83.1)$ & \\
\hline \multicolumn{10}{|c|}{ Received appropriate guidelines on updated procedures related to personal safety to follow at work } \\
\hline Yes & $37(16.3)$ & $190(83.7)$ & 0.36 & $68(29.9)$ & $159(70.1)$ & 0.17 & $37(16.3)$ & $190(83.7)$ & 0.36 \\
\hline No & $12(21.4)$ & $44(78.6)$ & & $22(39.3)$ & $34(61.7)$ & & $12(83.7)$ & $44(78.6)$ & \\
\hline \multicolumn{10}{|c|}{ Institution provided adequate PPE } \\
\hline Yes & $33(16.4)$ & $168(83.6)$ & 0.53 & $59(29.3)$ & $142(70.7)$ & 0.16 & $33(16.4)$ & $168(83.6)$ & 0.53 \\
\hline No & $16(19.5)$ & $66(81.5)$ & & $31(37.8)$ & $51(62.2)$ & & $16(19.5)$ & $66(81.5)$ & \\
\hline \multicolumn{10}{|c|}{ Institution made psychological or mental health support available } \\
\hline Yes & $10(8.4)$ & $109(91.6)$ & 0.0007 & $23(19.3)$ & $96(80.7)$ & 0.0001 & $9(7.6)$ & $110(92.4)$ & 0.0002 \\
\hline No & $39(23.8)$ & $125(76.2)$ & & $67(40.8)$ & $97(59.2)$ & & $40(24.4)$ & $124(75.6)$ & \\
\hline \multicolumn{10}{|c|}{ Feeling that you are being pushed beyond your training } \\
\hline Yes & $26(22.2)$ & $91(77.8)$ & 0.06 & $53(45.3)$ & $64(64.7)$ & 0.00004 & $22(18.8)$ & $95(81.2)$ & 0.57 \\
\hline No & $23(13.8)$ & $143(86.2)$ & & $37(22.3)$ & $129(77.7)$ & & $27(16.2)$ & $139(83.8)$ & \\
\hline \multicolumn{10}{|c|}{ Redirected to activities related to COVID-19 } \\
\hline Yes & $22(15.2)$ & $122(84.8)$ & 0.36 & $42(29.2)$ & $102(70.8)$ & 0.23 & $23(15.9)$ & $121(84.1)$ & 0.54 \\
\hline No & $27(19.4)$ & $112(80.6)$ & & $48(34.5)$ & $91(65.5)$ & & $26(18.7)$ & $113(81.3)$ & \\
\hline \multicolumn{10}{|c|}{ Engaged in COVID-19 activities for } \\
\hline$\leq 30$ days & $8(11.9)$ & $59(88.1)$ & 0.18 & $19(28.4)$ & $48(61.6)$ & 0.51 & $10(14.9)$ & $57(85.1)$ & 0.55 \\
\hline$>30$ days & $41(19.2)$ & $175(81.8)$ & & $71(32.9)$ & $145(67.1)$ & & $39(18.1)$ & $177(81.9)$ & \\
\hline \multicolumn{10}{|c|}{ Quality of life impacted due to COVID-19 } \\
\hline Yes & $44(21.2)$ & $163(78.8)$ & 0.003 & $72(34.8)$ & $135(65.2)$ & 0.07 & $45(21.7)$ & $162(78.3)$ & 0.001 \\
\hline No/remained same & $5(6.6)$ & $71(93.4)$ & & $18(23.7)$ & $58(76.3)$ & & $4(5.3)$ & $72(94.7)$ & \\
\hline \multicolumn{10}{|c|}{ Ability to perform household activities affected due to COVID-19 } \\
\hline Yes & $44(18.8)$ & $190(81.2)$ & 0.15 & $80(34.2)$ & $154(65.8)$ & 0.06 & $45(19.2)$ & $189(80.8)$ & 0.06 \\
\hline No & $5(10.2)$ & $44(89.8)$ & & $10(20.4)$ & $39(79.6)$ & & $4(8.2)$ & $45(91.8)$ & \\
\hline
\end{tabular}


specialized clinics were established to meet the growing need of mental health care in HCWs to prevent mental illness. Web-based mental health wellness programme was established $24 \mathrm{~h}$, which was anonymous to provide psychological support to HCWs across the Kingdom [43]. The strategies included in such programmes were in line with the strategies evident from previous literature to provide psychological support to HCWs, which included psychological intervention support teams, psychological counselling, availability of helpline, online platforms for medical assistance $[44,45]$.

Controllable risk factors related to the workplace such as availability of the PPE, insufficient training and lack of sufficient information on clinical procedures were not significantly associated with increased psychological impact. However, previous literature reported high depression and stress in HCWs pressurized to work without PPE, while insufficient training was uniquely associated with a high level of anxiety [46] (also shown after severe acute respiratory syndrome [SARS]) [47] and lack of sufficient information on COVID-19 clinical practice being linked to high symptoms in all domains [46]. Although working for more than 30 days continuously with COVID-19 related activities was not significantly associated with increased DASS-21 scores, feeling of being pushed beyond training was significantly $(p=0.0004)$ associated with the increased score on the anxiety subscale. However, evidence from literature reported that increased workload was positively related to psychological disorders $[48,49]$.

Significantly high levels of depression $(p=0.003)$, anxiety $(p=0.07)$ and stress $(p=0.001)$ were evident in individuals who felt that quality of life was heavily impacted due to COVID-19 which is similar to previous studies reporting that psychological distress influences the quality of life $[50,51]$.

\section{Limitations}

Participation in online surveys involves self-selection and respondents may not be fully representative. However, this approach permitted a rapid response and ease in the distribution of the survey questionnaire. Nevertheless, these findings should be viewed with caution as they may not be generalisable since the sample size was small, non -randomized and not representative of the whole country. The scales used were self-report and not diagnostic but have strong validity and reliability and are commonly used, since the study design is cross-sectional but planned follow-up surveys will permit longitudinal analysis of effects and relationships. Additional factors such as personality type, coping skills, availability, type and timing of psychological intervention are not examined which may play a role in the mental health of HCWs.

\section{Conclusions}

In conclusion, the COVID-19 pandemic has had a significant negative mental health impact on the HCWs. The study strongly indicates that the provision of psychological support remarkably improved mental health in the HCWs. Therefore, psychological risk assessments should be carried out regularly based on the factors identified. Strict monitoring of mental health among HCWs should be carried out and those exhibiting severe symptoms should be referred to mental health services. Lastly, the provision of mental health services should be made available in all hospitals throughout the kingdom.

\section{Abbreviations}

COVID-19: Coronavirus disease 2019; HCW: Health care workers.

\section{Acknowledgements}

This research would not have been possible without the exceptional support of our Head of the Department, Dr. Ahmed H. Qassem of Laboratory Medicine, Faculty of Applied Medical Sciences, Umm Al-Qura University.

\section{Authors' contributions}

SS: Conceptualization, Methodology, Validation, Formal analysis, Investigation, Resources, Data curation, Writing - original draft, review and editing, Supervision, Project administration. MAB: Methodology, Validation, Formal analysis, Investigation, Resources, Data curation, review and editing, Supervision, Project administration. IN: Validation, Formal analysis, Data curation and editing. EOF: Validation, Formal analysis, Data curation review and editing. AT: Conceptualization, Methodology, Formal analysis, review and data collection. MSI: Conceptualization, Methodology, Software, Validation, data collection review and editing. RAS: Conceptualization, Methodology, Formal analysis, review and data collection: NMA: Conceptualization, Methodology, Formal analysis, review and data collection. The authors read and approved the final manuscript.

\section{Funding}

This research did not receive any grant from funding agencies in the public, commercial or not-for-profit sectors.

Availability of data and materials

Included in supplementary file

\section{Declarations}

\section{Ethics approval and consent to participate}

Since it was a survey study, ethical permission was not needed. However, institutional review board permission was obtained, the questionnaire included a consent to participate and anonymity of the participants was strictly maintained.

\section{Consent for publication}

Not applicable.

\section{Competing interests}

The author declares they have no competing interests.

\section{Author details}

${ }^{1}$ Clinical Science Department, Fakeeh College for Medical Sciences, Jeddah, Saudi Arabia. ${ }^{2}$ Department of Community Medicine and Family Medicine, AlIMS, Gorakhpur, UP, India. ${ }^{3}$ Department of Nursing Practices, Faculty of Nursing, Umm Al-Qura University, Mecca, Saudi Arabia. ${ }^{4}$ Department of Laboratory Medicine, College of Applied Medical Sciences, Umm Al-Qura University, Mecca, Saudi Arabia. ${ }^{5}$ Department of Psychiatry, Eradah and Mental Health Complex, Jeddah, Saudi Arabia. ${ }^{6}$ Department of Medicine, China Medical University, Taichung City, People's Republic of China. 
Received: 2 November 2021 Accepted: 3 January 2022

Published online: 19 January 2022

\section{References}

1. Li Q, Guan X, Wu P, Wang X, Zhou L, Tong Y et al (2020) Early transmission dynamics in Wuhan, China, of novel coronavirus-infected pneumonia. N Engl J Med 382:1199-1207

2. MCAlonan GM, Lee AM, Cheung V et al (2007) Immediate and sustained psychological impact of an emerging infectious disease outbreak on health care workers. Can J Psychiat. 52(4):241-247

3. Tam CW, Pang EP, Lam LC, Chiu HF (2004) Severe acute respiratory syndrome (SARS) in Hong Kong in 2003: stress and psychological impact among frontline healthcare workers. Psychol Med. 34(7):1197-1204

4. Grace SL, Hershenfield K, Robertson E, Stewart DE (2005) The occupational and psychosocial impact of SARS on academic physicians in three affected hospitals. Psychosomatics 46(5):385-391

5. Bridgland VME, Moeck EK, Green DM, Swain TL, Nayda DM, Matson LA, Hutchison NP, Takarangi MKT Why the COVID-19 pandemic is a traumatic stressor 2021. r. PLoS One 16(1):e0240146 https://doi.org/10.1371/journal. pone.0240146

6. Etmann CK, Abdalla SM, Cohen GH, Sampson L, Vivier PM, Galea S (2020) Prevalence of depression symptoms in US adults before and during the COVID-19 pandemic 2020. JAMA Netw Open. 3(9):e2019686. https://doi. org/10.1001/jamanetworkopen.2020.19686

7. Pierce M, Hope H, Ford T, Hatch S, Hotopf M et al (2020) Mental health before and during the COVID-19 pandemic: a longitudinal probability sample survey of the UK population 2020. Lancets Psychiatry https://doi. org/10.1016/S2215-0366(20)30308-4

8. Kisely S, Warren N, McMahon L et al (2020) Occurrence, prevention, and management of the psychological effects of emerging virus outbreaks on healthcare workers: rapid review and meta-analysis. BMJ 369:m1642

9. Pappa S, Ntella V, Giannakas T et al (2020) Prevalence of depression, anxiety, and insomnia among healthcare workers during the COVID-19 pandemic: a systematic review and meta-analysis. Brain Behav Immun 88:901-907

10. Lai J, Ma S, Wang Y, Cai Z, Hu J, Wei N et al (2020) Factors associated with mental health outcomes among health care workers exposed to coronavirus disease 2019. JAMA Netw Open. 3(3):e203976

11. Huang JZ, Han MF, Luo TD, Ren AK, Zhou XP (2020) Mental health survey of 230 medical staff in a tertiary infectious disease hospital for COVID-19. Chin J Ind Hyg Occup Dis. 38(0):E001

12. Al-Hanawi MK, Mwale ML, Alshareef N, Qattan AMN, Angawi K, Almubark R et al (2020) Psychological Distress Amongst Health Workers and the General Public During the COVID-19 Pandemic in Saudi Arabia. Risk Management and Healthcare. Policy. 13:733-742

13. AlkhameesAA ASA, Alzunaydi AA, Almohimeed AS, Aljohani MS (2020) The psychological impact of COVID-19 pandemic on the general population of Saudi Arabia. Compr Psychiatry 102:152192

14. Chew NWS, Ngiam JN, Tan BYQ, Tham SM, Tan CYS et al (2020) AsianPacific perspective on the psychological well-being of healthcare workers during the evolution of the COVID-19 pandemic 2020. BJPsych Open. 6(6) e1 16.Published online 2020 Oct 8. https://doi.org/10.1192/bjo.2020.98

15. Chew NWS, Lee JKH, Tan BYQ, Jing M, Goh Y et al (2020) A multinational, multicentre study on the psychological outcomes and associated physical symptoms amongst healthcare workers during COVID-19 outbreak. Brain Behav Immun. 88:559-565. https://doi.org/10.1016/j.bbi.2020.04.0499

16. Lovibond SH, Lovibond PF (1995) Manual for the Depression Anxiety Stress Scales, 2nd edn. Psychology Foundation of Australia

17. Antony MM, Cox BJ, Enns MW, Bieling PJ, Swinson RP (1998) Psychometric properties of the 42 -item and 21 -item versions of the depression anxiety stress scales in clinical groups and a community sample. Psychol Assess. 10:176-181 https://doi.org/10.1037/1040-3590.10.2.176

18. Le MTH, Tran TD, Holton S, Nguyen HT, Wolfe R, Fisher J (2017) Reliability, convergent validity and factor structure of the DASS-21 in a sample of Vietnamese adolescents. PLoS One. 12(7):e0180557

19. Alhurishi SA, Almutairi KM, Vinluan JM, Aboshaiqah AE, Marie MA (2021) Mental Health Outcomes of Healthcare Providers During COVID-19 Pandemic in Saudi Arabia: A Cross-Sectional Study. Front Public Health https://doi.org/10.3389/fpubh.2021.625523
20. Al Ammari M, SultanKa TA, Swaidan A, Al HN (2021) Mental Health Outcomes Amongst Health Care Workers During COVID 19 Pandemic in Saudi Arabia. Front Psychiatry. 11:619540 https://doi.org/10.3389/fpsyt. 2020.619540

21. AlAteeq DA, Aljhani S, Althiyabi I, Majzoub S (2020) Mental health among healthcare providers during coronavirus disease (COVID-19) outbreak in Saudi Arabia. J Infect Public Health 13:1432-1437 https://doi.org/10. 1016/j.jiph.2020.08.013

22. Temsah MH, Al-Sohime F, Alamro N et al (2020) The psychological impact of COVID-19 pandemic on health care workers in a MERS-CoV endemic country. J Infect Public Health 13(6):877-882

23. Alqutub S, Mahmoud M, Baksh T (2021) Psychological Impact of COVID19 on Frontline Healthcare Workers in Saudi Arabia. Cureus. https://doi. org/10.7759/cureus. 15300

24. Al Muharraq EH, MSN, RN. The Psychological Impact of Coronavirus Disease 2019 on Nurses in Saudi Arabia and Their Coping Strategies. SAGE open nursing. https://doi.org/10.1177/23779608211011322.

25. Koh D, Lim MK, Chia SE, Ko SM, Qian F, Ng V et al (2005) Risk perception and impact of severe acute respiratory syndrome (SARS) on work and personal lives of health care workers in Singapore what can we learn? Med Care 43:6

26. Maunder RG (2004) Factors associated with the psychological impact of severe acute respiratory syndrome on nurses and other hospital workers in Toronto. Psychosom Med. 66(6):938-942

27. Chan AO, Huak CY (2004) Psychological impact of the 2003 severe acute respiratory syndrome outbreak on health care workers in a medium size regional general hospital in Singapore. Occup Med (Oxford, England) 54(3):190-196

28. Liu C-Y (2020) The prevalence and influencing factors in anxiety in medical workers fighting COVID-19 in China: a cross-sectional survey. Epidemiol Infect 148:e98-e9e

29. Du J (2020) Psychological symptoms among frontline healthcare workers during COVID-19 outbreak in Wuhan. Gen Hosp Psychiatr S0163-8343(20):30045-30041

30. Dutheil F (2019) Suicide among physicians and health-care workers: a systematic review and meta-analysis. PLoS One. 14(12):e0226361-e

31. Babore A (2020) Psychological effects of the COVID-2019 pandemic: perceived stress and coping strategies among healthcare professionals. Psychiatr Res. 293:113366

32. Pouralizadeh M (2020) Anxiety and depression and the related factors in nurses of guilan university of medical sciences hospitals during COVID19: a web-based cross-sectional study. Int J Afr Nurs Sci. 13:100233

33. Romero C-S, Catal $\tilde{A}_{j} J$, Delgado C, Ferrer C, Errando C; Iftimi A, Benito A, De Andres J, Otero M (2020) COVID-19 Psychological Impact in 3109 Healthcare workers in Spain: The PSIMCOV Group. Psychol Med. 1-14. https://doi.org/10.1017/S0033291720001671

34. Elbay RY (2020) Depression, anxiety, stress levels of physicians and associated factors in Covid-19 pandemics. Psychiatr Res 290:113130

35. Mo Y, Deng L, Zhang L, Lang Q, Liao C, Wang N, Qin M, Huang H (2020) Work stress among Chinese nurses to support Wuhan for fighting against the COVID-19 epidemic. J Nursing Manage. https://doi.org/10.1111/jonm.13014

36. Lu W (2020) Psychological status of medical workforce during the COVID19 pandemic: a cross-sectional study. Psychiatr Res 288:112936

37. Zhang WR (2020) Mental health and psychosocial problems of medical health workers during the COVID-19 epidemic in China. Psychother Psychosom.:1-9

38. Juan Y (2020) Psychological distress surveillance and related impact analysis of hospital staff during the COVID-19 epidemic in Chongqing, China. Compr Psychiatr.:152198

39. Rossi R (2020) Mental health outcomes among frontline and second-line health care workers during the coronavirus disease 2019 (COVID-19) pandemic in Italy. JAMA Network Open. 3(5):e2010185-e

40. Powell T, Yuma-Guerrero P (2016) Supporting community health workers after a disaster: findings from a mixed-methods pilot evaluation study of a psychoeducational intervention. Disaster Med Public Health Prep 10:754-761

41. Roberts NP, Kitchiner NJ, Kenardy J et al (2019) Early psychological intervention following recent trauma: a systematic review and metaanalysis. Eur J Psychotraumatol 10:1695486

42. Roberts N, Kitchiner N, Kenardy J (2010) Early psychological interventions to treat acute stress symptoms. Cochrane Database Syst Rev 3:CD007944

43. Banjar WM, Alaqeel MK (2020) Healthcare worker's mental health dilemma during COVID-19 pandemic: a reflection on the KSA experience. 
J Taibah Univ Med Sci. 15:255-257. https://doi.org/10.1016/j.jtumed.2020 06.006

44. Pfefferbaum B, North CS (2020) Mental health and the Covid-19 pandemic. N Engl J Med. 383:510-512. https://doi.org/10.1056/NEJMp20080 17

45. Shaukat N, Ali DM, Razzak J (2020) Physical and mental health impacts of COVID19 on healthcare workers: a scoping review. Int J Emerg Med. 13:40. https://doi.org/10.1186/s12245-020-00299

46. Gilleen J, Santaolalla A, Valdearenas L, Salice C, Fuste M (2021) Impact of COVID-19 pandemic on mental health and well being of UK health care workers. BJPsych Open. 3:7. https://doi.org/10.1192/bjo.2021.42

47. Maunder R, Lancee W, Balderson K, Bennett J, Borgundvaag B, Evans $S$ et al (2006) Long-term psychological and occupational effects of providing hospital healthcare during SARS outbreak. Emerg Infect Dis 12:1924-1932

48. Al Sulais E, Mosli M, AlAmeel T (2020) The psychological impact of COVID19 pandemic on physicians in Saudi Arabia: a cross-sectional study. Saudi J Gastroenterol. 26:249-255. https://doi.org/10.4103/sjg.SJG_174_20

49. Zhou Y, Wang W, Sun Y, Qian W, Liu Z, Wang R et al (2020) The prevalence and risk factors of psychological disturbances of frontline medical staff in china under the COVID-19 epidemic: workload should be concerned. J Affect Disord. 277:510-514. https://doi.org/10.1016/j.jad.2020.08.059

50. Asadi P, Ahmadi S, Abdi A, Shareef OH, Mohamadyari T, Miri J (2019) Relationship between self-care behaviors and quality of life in patients with heart failure. Heliyon 5(9):e02493. https://doi.org/10.1016/j.heliyon.2019. e02493

51. Gamage N, Senanayake S, Kumbukage M, Mendis J, Jayasekara A (2020) The prevalence of anxiety and its association with the quality of life and illness severity among bipolar affective disorder patients in a developing country. Asian J Psychiatr. 52:102044

\section{Publisher's Note}

Springer Nature remains neutral with regard to jurisdictional claims in pub-

lished maps and institutional affiliations.

\section{Submit your manuscript to a SpringerOpen ${ }^{\circ}$ journal and benefit from:}

- Convenient online submission

- Rigorous peer review

- Open access: articles freely available online

- High visibility within the field

- Retaining the copyright to your article

Submit your next manuscript at $\boldsymbol{\nabla}$ springeropen.com 